\title{
Microalbuminuria in Type 2 Diabetes and its Relationship with Glycosylated Hemoglobin
} \author{
Uddin Ahmed ${ }^{7 *}$ and Tuhin Sultana ${ }^{8}$ \\ ${ }^{1}$ Department of Laboratory Medicine, Bangabandhu Sheikh Mujib Medical University, Bangladesh \\ ${ }^{2}$ Department of Transfusion Medicine and Clinical Haematology, BIRDEM General Hospital, Bangladesh \\ ${ }^{3}$ Department of Laboratory Medicine, Bangabandhu Sheikh Mujib Medical University, Bangladesh \\ ${ }^{4}$ Department of Laboratory Medicine, Bangabandhu Sheikh Mujib Medical University, Bangladesh \\ ${ }^{5}$ Department of Endocrinology, Bangabandhu Sheikh Mujib Medical University, Bangladesh \\ ${ }^{6}$ Department of Laboratory Medicine, Bangabandhu Sheikh Mujib Medical University, Bangladesh \\ ${ }^{7}$ Masters in Microbiology, Bangladesh University of Professionals, Bangladesh \\ ${ }^{8}$ Department of Laboratory Medicine, Bangabandhu Sheikh Mujib Medical University, Bangladesh
}

Sheuly Ferdousi ${ }^{1}$, Tania Nasreen ${ }^{2}$, Saiful Islam³ ${ }^{3}$ Quddusur Rahman ${ }^{4}$, Shahjada Selim ${ }^{5}$, Debatosh Paul ${ }^{6}$, Mesbah

Submission: April 16, 2019; Published: May 02, 2019

*Corresponding author: Mesbah Uddin Ahmed, Masters in Microbiology, Bangladesh University of Professionals, Bangladesh

Abstract

Background: Microalbuminuria is the most common aetiology of chronic kidney disease. Optimum glycemic control reduces the development and progression of diabetes-related complications and there is evidence that improved glycemic control improves outcome in diabetic subjects

Objective: This study was designed to know the relationship of glycosylated hemoglobin (HbA1c) level with microalbuminuria and normoalbuminuria in type 2 diabetic patients and its relation to diabetic nephropathy.

Materials and Methods: This study was conducted at the Department of Laboratory Medicine (Clinical Pathology) in collaboration with Endocrinology department (BSMMU), Dhaka. In this study, HbA1c level and urine microalbumin level of 60 type 2 diabetic patients were measured. Both levels were measured by biochemical auto analyzer (Siemens Dimension RL Max).

Results: Urinary microalbumin, HbA1c levels were significantly higher in the cases. Microalbumin levels were linearly correlated to the duration of diabetes and $\mathrm{HbA} 1 \mathrm{c}$.

Conclusion: Impaired glycemic control is associated with significant elevations in urinary microalbumin levels. Furthermore, there is an increased urinary microalbumin levels with increased duration of diabetes, which suggests that the detection of increased urinary microalbumin levels at the initial stage can avert, reduce the clinical and economic burden of diabetic complications in future.

Keywords: Glycemic control; Microalbumin levels; Diabetic complications; Blood glucose level; Hyperglycemia; Diabetic nephropathy; Macroalbuminuria; Diabetes-related complications; Malabsorption; Chronic diarrhea; Hyperglycemia; Exercise; Urinary tract infections; Marked hypertension; Heart failure; Acute febrile illness; Dehydration

Abbreviations: ESKD: End-Stage Kidney Disease; UAE: Urinary Albumin Excretion; PETINIA: Particle-Enhanced Turbidimetric Inhibition Immunoassay; MALB: Microalbumin

\section{Introduction}

Diabetes mellitus is a clinical condition characterized by increased blood glucose level (hyperglycemia) due to insufficient or inefficient (incompetent)insulin [1]. The incidence of diabetes is rising. As a result, Diabetic nephropathy is more common now a days and an important cause of morbidity and mortality in chronic kidney disease and end-stage kidney disease (ESKD) or failure [2]. Improved glycemic control has been demonstrated to reduce micro and macro vascular complications in patients with diabetes. Glycated hemoglobin (HbA1c) is the preferred and widely utilized biomarker of glycemic control in subjects with diabetes with higher concentrations of glucose [3]. Diabetic nephropathy is defined by increased urinary albumin excretion (UAE) in the absence of other renal diseases. It is categorized into two stages: microalbuminuria (UAE $\geq 20 \mathrm{microg} / \mathrm{min}$ and $\leq 199 \mathrm{microg} / \mathrm{min}$ ) and macroalbuminuria (UAE $\geq 200 \mathrm{microg} /$ 


\section{Current Research in Diabetes \& Obesity Journal}

min). Hyperglycemia, increased blood pressure levels and genetic predisposition are the main risk factors for the development of diabetic nephropathy [4]. HbA1c is currently accepted as the most informative biomarker of glycemic control in subjects with diabetes and is highly prognostic for long-term diabetes-related complications such as microalbuminuria [5].

\section{Materials and Methods}

This cross-sectional study was conducted at the Department of Laboratory Medicine (Clinical Pathology) in collaboration with Department of Endocrinology, BSMMU, Dhaka. Total 60 subjects of type 2 diabetes mellitus were included. Urinary microalbumin levels and $\mathrm{HbA} 1 \mathrm{c}$ in all type 2 diabetic patients were measured. Urinary microalbumin was measured by microalbumin (MALB) method which had been based on a particle-enhanced turbidimetric inhibition immunoassay (PETINIA) in biochemical auto analyzer (Siemens Dimension RL Max). Other types of diabetes, patients with UTI/ Pyelonephritis, patients who were on long term diuretics, with malabsorption or chronic diarrhea, on dialysis were excluded.

Table 2: Distribution of the patient's age by urine micro albumin $(n=60)$

\section{Result}

Total 60 subjects of type 2 diabetes mellitus were included. HbA1c level and urine microalbumin level were measured. After performing microalbumin in urine, patients were grouped into normoalbuminuria and microalbuminuria. Finally, correlation coefficient of HbA1c and urinary microalbumin was calculated by using Pearson's correlation coefficient test.

Table 1: Distribution of the patients by urine micro albumin $(n=60)$

\begin{tabular}{|c|c|c|}
\hline Urine Microalbumin (mg/L) & Frequency & Percent \\
\hline Normoalbuminuria $(<20)$ & 31 & 51.7 \\
\hline Microalbuminuria $(\geq 20)$ & 29 & 48.3 \\
\hline Total & 60 & 100 \\
\hline Mean \pm SD (Min-Max) & $36.69 \pm 44.21(2-145)$ & \\
\hline
\end{tabular}

Table 1 shows urine microalbumin of the study patients, it was observed that $29(48.3 \%)$ patients had microalbuminuria and $31(51.7 \%)$ normoalbuminuria. The mean microalbumin level was found $36.69 \pm 44.21 \mathrm{mg} / \mathrm{L}$ with range from $2-145 \mathrm{mg} / \mathrm{L}$.

\begin{tabular}{|c|c|c|c|}
\hline \multirow{2}{*}{ Age (Years) } & \multicolumn{2}{|c|}{ Urine Micro Albumin (mg/L) } & \multirow{2}{*}{ p Value* } \\
\cline { 2 - 3 } & Normoalbuminuria (<20) & Microalbuminuria ( $\mathbf{2 0} \mathbf{2 0}$ & \\
\hline$\leq 35$ & $7(22.6)$ & $4(13.8)$ & \\
\hline $35-45$ & $7(22.6)$ & $4(13.8)$ & \\
\hline $45-55$ & $11(35.5)$ & $12(41.4)$ & \\
\hline$>55$ & $6(19.4)$ & $29(31.0)$ & \\
\hline Total & $31(100.0)$ & $49.55 \pm 10.46$ & 0.386 \\
\hline Mean \pm SD & $47.10 \pm 11.24$ & & \\
\hline
\end{tabular}

*t test was done to measure the level of significance.

Table 2 shows the age distribution of study population. The mean age was found $49.55 \pm 10.46$ years in microalbuminuria group, $47.10 \pm 11.24$ years in normoalbuminuria group and. The

difference was statistically not significant ( $p>0.05$ ) between two group. Figure within parentheses indicates in percentage.

Table 3: Distribution of the patients' sex by urine micro albumin

\begin{tabular}{|c|c|c|c|}
\hline \multirow{2}{*}{ Sex } & \multicolumn{2}{|c|}{ Urine Micro Albumin (mg/L) } & \multirow{2}{*}{ p Value* } \\
\hline & Normoalbuminuria $(<20)$ & Microalbuminuria $(\geq 20)$ & \\
\hline Male & $20(64.5)$ & $15(51.7)$ & \\
\hline Female & $11(35.5)$ & $14(48.3)$ & 0.315 \\
\hline Total & $31(100.0)$ & $29(100.0)$ & \\
\hline
\end{tabular}

${ }^{*} t$ test was done to measure the level of significance.

Figure within parentheses indicates in percentage.

Table 3 shows comparison between sex with urine microalbuminuria, it was observed that almost half of the male patients $15(51.7 \%)$ patients were male in microalbuminuria group and 20 (64.5\%) in normoalbuminuria group. The difference was statistically not significant $(\mathrm{p}<0.005)$ between two group.

Figure within parentheses indicates in percentage.

Table 4: Distribution of the patients HbA1c by urine micro albumin $(n=60)$

\begin{tabular}{|c|c|c|c|}
\hline \multirow{2}{*}{ HbA1c (\%) } & \multicolumn{2}{|c|}{ Urine Micro Albumin (mg/L) } & \multirow{2}{*}{ p Value* } \\
\cline { 2 - 3 } & Normoalbuminuria (<20) & Microalbuminuria ( $\mathbf{2 0}$ ) & \\
\hline Normal $(<6.5)$ & $9(29.0)$ & $3(10.3)$ & \\
\hline Raised $(>6.5)$ & $22(71.0)$ & $26(89.7)$ & \\
\hline
\end{tabular}




\section{Current Research in Diabetes \& Obesity Journal}

\begin{tabular}{|c|c|c|c|}
\hline Total & $31(100.0)$ & $29(100.0)$ & \\
\hline Mean \pm SD & $7.53 \pm 1.72$ & $7.90 \pm 1.69$ & 0.04 \\
\hline
\end{tabular}

$*_{t}$ test was done to measure the level of significance.

Figure within parentheses indicates in percentage.

Table 4 shows distribution of the patients HbA1c by urine micro albumin. 26(89.7\%) had raised HbA1c in microalbuminuria group. 22(71.0\%) had raised HbA1c in normoalbuminuria group. The difference was statistically significant $(\mathrm{p}<0.05)$ between two groups.

\section{Discussion}

Microalbuminuria includes a range of urinary excretion of albumin of 20 to $200 \mathrm{mg} / \mathrm{L}$ or 20 to $200 \mu \mathrm{g} / \mathrm{min} \mathrm{[6].} \mathrm{The}$ causes of microalbuminuria include short term hyperglycemia, exercise, urinary tract infections, marked hypertension, heart failure, acute febrile illness, dehydration. Some others condition that damage glomerulous causes microalbuminuria and then progress toward microalbuminuria to proteinuria. Such conditions are hypertension, diabetes, vasculitis etc. [6,7].

The findings of this study are compared with the results of some other published articles elsewhere in the world to verify the results. In this study, urinary microalbumin level was measured in 60 subjects of type 2 diabetes mellitus., it was observed that $29(48.3 \%)$ patients had microalbuminuria and $31(51.7 \%)$ normoalbuminuria. The mean microalbumin level was found $36.69 \pm 44.21 \mathrm{mg} / \mathrm{L}$ with range from $2-145 \mathrm{mg} / \mathrm{L}$. Xu B et al. [8] had shown that $11.37 \%$ of the study population had microalbuminuria, in another study done by Varghese et al. [9] found that overall prevalence of microalbuminuria $36.3 \%$. So, the findings of present study are within the range of previously published studies, but more than the study done by Xu B et al. [8]. This difference in result might be due to demographical variation. It was observed that in normoalbuminuria group, the mean age was found $49.55 \pm 10.46$ years in microalbuminuria group, $47.10 \pm 11.24$ years in normoalbuminuria group and. The difference was statistically not significant $(p>0.05)$ between two group.

In a study done by Anesh $\mathrm{T}$ et al. [10] found that the mean age of microalbuminuria group was $57.15 \pm 10.17$. This difference in result might be due to demographical variation. In present study, it was observed that almost half of the male patients 15 (51.7\%) patients were male in microalbuminuria group and 20 (64.5\%) in normoalbuminuria group. The difference was not statistically significant $(\mathrm{p}>0.005)$ between two group. In a study done by Anesh $\mathrm{T}$ et al. [10] found that $63.8 \%$ microalbuminic patients were male. In another study, Rao PP et al. [4] shown that about $66 \%$ were males and $34 \%$ were females in both groups. This difference in result might be due to demographical variation and socioeconomic status. In present study, 26(89.7\%) had raised $\mathrm{HbA} 1 \mathrm{c}$ in microalbuminuria group and $22(71.0 \%)$ had raised $\mathrm{HbA1c}$ in normoalbuminuria group. The difference was statistically significant $(\mathrm{p}<0.05)$ between two groups. Gupta $M$ et al. [11] also found a significant correlation between HbA1c and microalbuminuria. So, the result of present study is consistent with other studies. Based on observations of present study, level of glycemic control seems to be the strongest factor determining conversion from normoalbuminuria to microalbuminuria in patients with type 2 diabetes mellitus. As such this study will fill the gap, open new forum of discussion and will provide knowledge and information regarding the medical workup of patients with type-2 diabetes mellitus.

\section{Conclusion}

This necessitates that all type 2 diabetes mellitus should be screened for HbA1c and urine microalbumin level along with blood glucose level. Any abnormal level should be treated meticulously to revert or prevent microalbuminuria and thus delay complications.

\section{References}

1. (2013) American Diabetic Association, Diagnosis and classification of diabetes mellitus. Diabetes Care 36(1): S67-S74.

2. Vos FE, Schollum JB, Walker RJ (2011) Glycated albumin is the preferred marker for assessing glycaemic control in advanced chronic kidney disease. NDT plus 4(6): 368-375.

3. Goldstein DE, Little RR, Lorenz RA, Malone JI, Nathan D, et al. (2004) Tests of Glycemia in Diabetes. Diabetes Care 27(7): 1761-1773.

4. Rao PP, Shariff MG (2015) Serum magnesium levels in type 2 diabetic patients with microalbuminuria and normoalbuminuria. International Journal of Scientific Study 3(4): 11-15.

5. Borg R, Kuenen JC, Carstensen B, Zheng H, Nathan DM, et al. (2011) HbA1c and mean blood glucose show stronger associations with cardiovascular disease risk factors than do postprandial glycaemia or glucose variability in persons with diabetes: the A1C-Derived Average Glucose (ADAG) study. Diabetologia 54(1): 69-72.

6. McPherson RA, Ben-Ezra J (2007) Basic Examination of Urine. In: Mc Pheson RA, Pincus MR (Edt.), Henry's Clinical Diagnosis and Management by Laboratory Methods, ( $21^{\text {st }}$ edn.), Elsevier, New Delhi, India.

7. Pearson ER, McCrimmon RJ (2014) Diabetes Mellitus. In: BR Walker, NR Colledge, SH Ralston, ID Penman (Edt.), Davidson's Principles \& Practice of Medicine. (22 ${ }^{\text {nd }}$ edn.), Elsevier, Edinburgh: Churchill Livingstone, UK.

8. Xu B, Sun J, Deng X, Huang X, Sun W, et al. (2013) Low Serum Magnesium Level Is Associated with Microalbuminuria in Chinese Diabetic Patients. International Journal of Endocrinology pp. 1-6.

9. Varghese A, Deepa R, Rema M, Mohan V (2001) Prevalence of microalbuminuria in type 2 diabetes mellitus at a diabetes centre in southern India. Postgrad Med J 77(908): 399-402.

10. Aneesh T, Rao MY (2016) Serum magnesium in type 2 diabetic patients with microalbuminuria and overt proteinuria. IOSR-JDMS 15(1): 3035.

11. Gupta M, Singh JP (2017) Correlation of microalbuminuria with glycosylated haemoglobin in patients of diabetes having nephropathy. International Journal of advances in medicine 4(3): 805-808. 
(C) Commons Attribution 4.0 Licens

BY DOI: 10.19080/CRDOJ.2019.10.555795

Your next submission with Juniper Publishers will reach you the below assets

- Quality Editorial service

- Swift Peer Review

- Reprints availability

- E-prints Service

- Manuscript Podcast for convenient understanding

- Global attainment for your research

- Manuscript accessibility in different formats

( Pdf, E-pub, Full Text, Audio)

- Unceasing customer service

Track the below URL for one-step submission https://juniperpublishers.com/online-submission.php 